Juliana de Miranda e Castro-Arantes ${ }^{1}$

Anna Carolina Lo Bianco ${ }^{2}$

${ }^{1}$ Clínica da Dor, Instituto Nacional de Câncer José Alencar Gomes da Silva. Praça Cruz Vermelha 23 Centro. 20.230-130 Rio de Janeiro RJ.

juliana.castro@inca.gov.br

${ }^{2}$ Centro de Filosofia e

Ciências Humanas,

Universidade Federal do

Rio de Janeiro.

\title{
Corpo e finitude - a escuta do sofrimento como instrumento de trabalho em instituição oncológica
}

\author{
Body and finitude - listening to suffering \\ as a working tool in an oncological institution
}

\begin{abstract}
Based on the day-to-day care of patients in the Pain Clinic of a Brazilian cancer hospital (INCA), this article seeks to examine the consequences upon the psychic dimension of the fact of pain being intimately linked to the body. Almost always profoundly affected by the illness, the concept of the subject's own body deeply modifies this identification. This not only causes suffering, but also prejudices oncological treatment. Conceptualizing the body from a psychoanalytical standpoint, this article emphasizes the importance of language and the spoken word in its constitution, as the body perceived by psychoanalysis does not coincide with the biological body. The importance of listening to what the patients say is therefore seen as an important tool in the work of professionals in an oncological institution. Two possible positions regarding professionals dealing with the imminence of death and the finitude of life are then outlined. The first is refraining from being affected by the finite and perishable dimension of life, feeling pity for the patients, resigning and distancing oneself from their predicament. The second involves listening to the patients with compassion, acknowledging the inexorable finitude common to all, such that they may not suffer alone and share some of the horror they are experiencing.
\end{abstract}

Key words Cancer, Body, Finitude, Word, Listening
Resumo Partindo do cotidiano da assistência a pacientes que chegam à Clínica da Dor do Instituto Nacional de Câncer José Alencar Gomes da Silva (INCA), o artigo procura examinar as consequências que traz, para o psíquico, o fato dele estar indissociavelmente ligado ao corpo. Quase sempre afetada profundamente pela doença, a concepção do corpo próprio traz alterações importantes quanto à identificação do sujeito, acarretando disfunções psíquicas, que não só causam sofrimento, como comprometem o tratamento oncológico. Desenvolvendo a conceituação psicanalítica do corpo, ressalta a incidência da linguagem e da fala em sua constituição, que não coincide com a do corpo biológico. Em seguida demonstra que a escuta da fala do paciente, por parte do profissional, é um instrumento de trabalho fundamental em instituição oncológica. Conclui por caracterizar duas posições possíveis a serem ocupadas por aquele que lida com a morte e com a finitude: poupar-se a si próprio do encontro com a dimensão finita e perecível da vida, sentindo pena do paciente, resignando-se e demitindo-se desse encontro; ou escutá-lo com compaixão, reconhecendo o inexorável comum a todos, de modo a que o sujeito possa sofrer isso não tão sozinho e venha a elaborar na palavra algo do horror que atravessa.

Palavras-chave Câncer, Corpo, Finitude, Palavra, Escuta 


\section{Introdução}

Procuraremos no presente artigo examinar as consequências, para o psíquico, do fato de ele estar ligado ao corpo. Partiremos de questões suscitadas no cotidiano da assistência a pacientes que chegam à Clínica da Dor do Instituto Nacional de Câncer José Alencar Gomes da Silva (INCA). Observamos a cada vez que, quase sempre afetada profundamente pela doença, a concepção do corpo próprio traz alterações importantes quanto à identificação do sujeito ${ }^{1-3}$. Acarreta sérias disfunções psíquicas, que não só causam sofrimento, como muitas vezes comprometem o tratamento oncológico.

Veremos como um dos recursos para enfrentarmos os problemas assim surgidos reside na escuta da fala do paciente, uma vez que corpo e psíquico são articulados na e pela palavra daquele que a profere. Em nosso auxílio virá a própria definição de dor da International Association for the Study of Pain", que a considera "uma experiência sensorial e emocional desagradável, associada a uma lesão tissular real ou potencial, ou ainda descrita em termos dessa lesão". Esta definição pode ser complementada por outra que acrescenta que a "dor é seja o que for que aquele que a experiencia diz que é, e existe seja quando for que aquele que a experiencia diz que existe"s. Em ambas, a menção à expressão do paciente e a seu dizer são apontadas como a via principal de acesso ao padecimento em questão.

A referência à palavra do paciente, no que diz respeito ao corpo próprio e ao sofrimento que o atinge, portanto, constituirá a base do nosso trabalho. Este se apoiará nos fundamentos trazidos pela conceituação teórica da psicanálise, que concebe um corpo que não coincide com o corpo biológico e dá relevo à palavra ${ }^{6-10}$.

Ressaltar o valor da palavra e, portanto, se oferecer à sua escuta, ainda como veremos, será um meio de dar condições ao sujeito de enfrentar a dificuldade pela qual está passando. Encontramos aqui com a questão do papel, não apenas do psicólogo, mas de cada integrante da equipe multiprofissional que acolhe o paciente. Emprestar sua escuta e acompanhar o sujeito na dureza do que atravessa, coloca ao profissional uma exigência que certamente não será sem ônus para si próprio. Neste ponto, encontraremos a questão sobre aqueles que em sua vida lidam com os limites impostos por esta, e procuraremos ver como são eles afetados em suas próprias subjetividades.

\section{O corpo é pulsional, não é natural}

O fato de o psiquismo estar ligado ao corpo traz para o primeiro consequências importantes, pois qualquer alteração do corpo terá repercussão na ordem do psíquico. Para falar dessa ligação entre o corpo e o psiquismo, a psicanálise concebe o conceito de pulsão. Introduzindo uma complexificação do esquema fisiológico do reflexo, Freud ${ }^{7}$ faz uma distinção entre estímulos externos, dos quais é possível se livrar, e estímulos vindos do interior do organismo, dos quais não se pode fugir. Estes constituem a base da pulsão, um conceito que surge na fronteira entre o somático e o psíquico, para falar desses estímulos que provêm do interior do corpo e chegam ao psiquismo. A característica mais importante da pulsão é a de ser concebida como "uma medida da exigência de trabalho imposta ao psiquismo em consequência de sua ligação com o corporal" "Vale dizer, ao psiquismo é demandada sempre uma resposta pelo que acontece ao corpo. Nada que aconteça ao corpo, portanto, é indiferente ao psíquico, o que faz com que, a rigor, sequer se possa distingui-los nitidamente.

No humano, diferentemente do instinto animal, há pulsão, e, embora sujeito e pulsão não coincidam, não se pode falar em constituição subjetiva sem se tratar do campo pulsional. Além disso, se não há como pensar em instinto ou em biológico, no humano não há um corpo biológico de uma parte e um tanto pulsional de outro; isto é, não há como supor um corpo que não seja atingido pela questão do pulsional. $\mathrm{O}$ advento do sujeito está necessariamente ligado ao funcionamento pulsional, implicando que o sujeito é efeito do ritmo pulsional, sendo falado por um vocabulário em termos pulsionais. Ele virá ou não a se reconhecer como efeito desse ritmo, o que, seja como for, não será sem consequências para sua posição subjetiva, voltaremos a esse ponto adiante.

Ainda que, à primeira vista, tais afirmações contenham algo de enigma, nos ajudam por iluminar alguns impasses da clínica, permitindo que nos indaguemos em que a formulação de um circuito pulsional assim afetado auxilia no acompanhamento de um paciente. O que estará ele sofrendo com a concepção de um corpo próprio, enquanto um corpo agora modificado pelo câncer? Como estará o corpo que é agora submetido às intervenções do tratamento oncológico? Que consequências estão implicadas para a sua subjetividade? 
Desde que nasce, o humano, ainda não falante, é, no entanto, falado. Ele se constitui quando aqueles que cuidam falam dele, fazendo de seu organismo um corpo falado. A mãe encontra ou não no recém-nascido um corpo a ser agasalhado, alimentado, higienizado, acariciado, amado ou odiado. A cada ponto em que o corpo é ou não tomado, ele é ou não tomado em uma rede de significações constituídas pela palavra. Investindo o corpo com palavras, faz-se dele um corpo pulsional.

O sujeito é, então, efeito do investimento feito em seu corpo. Ele surge sujeito ao corpo pulsional ${ }^{6-8,11-13}$. O corpo do bebê, de início, era um bricabraque; dito de outra maneira, era um amontoado de órgãos. Massa amorfa que, ao ser recortada pela palavra vinda do Outro, se diferencia em arranjo de órgãos em função. É pelo dizer vindo do Outro, da linguagem, encarnada por sua mãe, que lhe vai ser dito o que ele é como humano. Sujeitando-se a trocas e aos significantes que estas veiculam, seus órgãos serão simbolizados e ele se reconhecerá como sujeito a um corpo. Por isso as pulsões são definidas como o "eco no corpo do fato de que há um dizer"14. São o modo como a linguagem atravessa o corpo, ou seja, como ele será afetado pelo eco cortante do dizer.

Esse recorte tem como efeito a erogeneização do corpo pela função dada aos seus orifícios, seguindo uma "gramática pulsional"15. O investimento pulsional circunscreve zonas erógenas: o que sustenta o corpo, o que faz sua consistência, é o fato de que, ao ser falado, se criam zonas diferenciadas, como se fossem cortadas e recortadas, dando ao corpo uma organização própria. O corpo constituído nessa pulsação tem sua gramática própria, não sendo da mesma ordem daquele que normalmente compreendemos através do olhar da biologia ou da anatomia. Com a psicanálise, o corpo é um objeto outro, que escapa de uma relação estabelecida naturalmente ${ }^{12}$. Não havendo como falar de um corpo lugar de instintos, de um corpo biológico, trata-se de reconhecer que não há constituição subjetiva fora do campo pulsional e, logo, do campo da palavra. Por isso dizemos que o sujeito é efeito do corpo pulsional.

A conjunção sujeito psíquico/corpo pulsional permite a Freud ${ }^{8}$ conceituar o eu como um eu corporal, um eu cuja essência é corpo. É neste ponto que ancoramos a concepção de dor que irá nos orientar no presente trabalho. O modo como, com as enfermidades dolorosas, se adquirem novas notícias de seus órgãos é paradig- mático de como se chega à representação do corpo próprio. A dor nos faz saber que temos um corpo; se não conseguimos dissipá-la, ficamos inteiramente investidos por ela. Freud ${ }^{16}$ chega mesmo a dar um exemplo prosaico em que, se referindo à nossa reação diante de uma dor de dente, diz que "nos transportamos inteiramente para o molar". E Leriche afirma que "a saúde é a vida no silêncio dos órgãos"12,17. Nos sentimos bem uma vez que não sentimos o corpo, que ele não faz falar dele.

O que talvez seja mais importante ressaltar são as consequências que se podem tirar dessa função da dor para o surgimento do corpo no campo da percepção. Com a dor, o corpo irrompe no campo perceptivo, dizendo de sua precariedade. Através da dor se sabe do corpo e, concomitantemente, de suas limitações e extensões. Falar de limitações e extensões do corpo é introduzir sua relação com dois temas aparentemente distintos, é enfatizar a ligação do corpo com a morte e com o sexo. Esta ligação torna-se visível no momento mesmo da reprodução. Tomamos esse momento como aquele crucial para pensarmos a relação corpo/morte/sexo, pois se trata aí da ocasião em que o corpo sexuado, com sua célula germinal, ao tempo em que perpetua a espécie tem notícia de seu limite como corpo individual, limitado, mortal ${ }^{16,18}$. Por sua relação com a morte e com o sexo, o corpo introduz a finitude, o perecível e a transitoriedade ${ }^{19}$.

A referência ao complexo de castração neste ponto é fundamental, porque ele nos permite situar a maneira de cada sujeito enfrentar os limites que lhe são impostos por um corpo sexual e mortal ${ }^{20}$. A maneira do sujeito se posicionar frente aos limites impostos pela castração engendra o modo como o sujeito organiza a relação com o Outro, suas modalidades discursivas, suas condutas sexuais e suas relações com os outros ${ }^{13,21}$. Ou seja, o complexo de castração é o que explica a maneira do sujeito se haver com impasses intransponíveis em sua vida. Desde que nasce e se encontra com os constrangimentos dados pelo $\operatorname{corpo}^{22}$ será instado a tomar uma posição pela qual será responsável. Aqui, mais uma vez, vemos que se trata no humano de uma montagem e não de algo prévio, da ordem do biológico, uma vez que a anatomia não garante a sexuação, vale dizer, há uma operação subjetiva em jogo.

No entanto, do fato da castração pouco queremos saber, ao contrário, buscamos o sentimento de bem estar que remete a ser "puramente espiritual, desprendido das contingências do corpo", que passa assim a ser um "corpo recalca- 
do" ${ }^{12}$. Isto é, mantemos o corpo afastado da consciência, recalcado, portanto inconsciente, e, no entanto, ele nos comanda em todas as circunstâncias da vida.

\section{O corpo pulsional e o sujeito do desejo}

Nos voltaremos agora para os estudos da psicose. Embora não estejamos nos endereçando neste artigo para a questão dos psicóticos, entendemos que esses pacientes nos ensinam sobre a estrutura psíquica de todo ser que se encontra com a linguagem. As disfunções que os acometem em sua relação com o corpo próprio nos permitem reconhecer outros fenômenos que dão novas notícias da constituição pulsional do corpo. Esperamos, assim, encontrar outros subsídios que nos auxiliem na escuta dos pacientes sob tratamento oncológico.

A psicanálise desenvolve a teoria que apreende tais fenômenos como indicadores de um funcionamento que, no entanto, é estrutural. O psicótico é tocado pela questão pulsional de maneira particularmente problemática. Reconhece-se de início na psicose o que ficou estabelecido como uma "desespecificação pulsional"13. Sobressai nesses casos uma não coincidência entre órgão e função. Se do ponto de vista da biologia a cada órgão corresponderiam uma ou mais funções específicas, ou seja, por exemplo, às cavidades bucal e oral, corresponderiam as funções de ingestão de alimentos, de respiração e de emissão de sons para a comunicação, na psicose encontramos pacientes cuja boca está ligada antes à evacuação de fezes. Da mesma maneira, verificamos que ao ânus, aos intestinos, aos esfíncteres não está relacionada a função de defecar, pois estes se encontram, na lógica delirante, obturados, não permitindo a passagem das fezes.

É o caso do paciente J.R., morador do Hospital Psiquiátrico de Jurujuba, instituição com a qual o INCA mantém um convênio no âmbito do Programa de Residência Multiprofissional em Oncologia. J.R. apresentava quadro de anorexia grave por se recusar a ingerir alimentos, e, sem qualquer afecção orgânica, tinha a convicção delirante de que seu ânus estava fechado e, caso viesse a se alimentar, as fezes sairiam por sua boca. Como ele próprio afirmava à época, "a comida entope, na hora de evacuar não desce". Observamos um desligamento entre órgão e função: ânus obturado por onde não defeca, boca onde não deve entrar a comida sob pena de por ela sairem fezes. É o discurso que vem ligar os órgãos em função ${ }^{13} \mathrm{e}$, na psicose, essa junção não se efetua, uma vez que função e órgão seguem desarticulados, caracterizando os referidos fenômenos de desespecificação pulsional.

A psicose mais uma vez nos ensina que as funções corporais nem sempre coincidem com as estabelecidas pela fisiologia e pela biologia. É importante observarmos se e como a desespecificação pulsional, que opera na psicose, contribui para pensarmos o circuito pulsional na neurose, ou seja, nos indagarmos se a oralidade psicótica pode esclarecer um destino pulsional que não seria restrito a essa estrutura ${ }^{23}$.

Enfim, recorremos a textos sobre o corporal na psicose, abordando os elementos estruturalmente e não fenomenologicamente, por entendermos que nessa estrutura encontramos de forma pungente a montagem, recalcada na neurose, que está em jogo na constituição do que chamamos corpo próprio. A psicose nos mostra que o corpo concebido pela psicanálise, com a marca da palavra e da pulsão, contribui para as questões com as quais nos havemos na clínica de pacientes em instituição oncológica, quase sempre de estrutura neurótica. Trata-se nessa clínica de um endereçamento ao sujeito que padece, no momento mesmo em que seu desejo está vivamente em questão.

Para avançarmos na problemática do sujeito e seu desejo, vale recorrermos ainda à distinção entre uma "pulsão subjetivante" e outra "dessubjetivante". Essa distinção foi realizada por Vandermersch ${ }^{24}$, quem, tratando de uma paciente bulímica, notou nela um conflito entre, de um lado, um funcionamento que aponta na direção de seu desejo e, de outro, um que não dá lugar a ela como sujeito - o qual triunfa, a despeito dela mesma. Ao falar desse conflito, a paciente faz uma mudança sintática em sua fala, passando do eu (quando fala de uma posição desejante) ao se impessoal. O autor afirma tratar-se, na verdade, de um conflito entre uma pulsão subjetivante e uma pulsão dessubjetivante. Em linhas gerais, faz uma distinção entre o que chama funcionamento subjetivante da pulsão - o qual tem efeito de sujeito, que ele equivale ao desejo -, e outro que não produz sujeito. Neste, temos um funcionamento não subjetivante da pulsão, que opera de modo acéfalo. A pulsão acéfala é empuxo permanente, pulsão que não prepara a vinda do desejo. Para sumarizar, há, então, pulsão dessubjetivante, a qual opera de modo acéfalo, em que não há um "efeito sujeito" - note-se que não se está falando mais aqui de psicose, mas de casos de bulimia e toxicomania - e pulsão subjetivante, equivalente ao desejo, e que tem "efeito sujeito" ${ }^{24}$. 


\section{A palavra: lugar do sujeito do desejo}

L.D. é encaminhada para acompanhamento psicológico por sua médica, quem, apesar de toda a bateria medicamentosa a que submete a paciente, não consegue controlar a dor. No entanto, logo nas primeiras entrevistas, L.D. reporta o fato de que, até chegar a um atendimento de rotina com a fisioterapeuta, seguido à mastectomia que sofrera, "não sentia dor". "Foi quando ela [a fisioterapeuta] disse 'isso que você tem é dor' que eu passei a chorar de dor". E, acrescenta: "é muita dor, não há o que fazer para passar". É notável que uma dor agora tão incontrolável, que traz impedimentos importantes para sua condição, justo antes dessa palavra, não aparecesse. Ao investigarmos junto com a paciente, escutamos a sua surpresa ao se encontrar com a falta de explicação para isso.

Freud $^{8}$ afirma que a dor pode permanecer inconsciente. No caso de L.D. é possível falarmos de uma força pulsionante sendo liberada sem que o "eu" notasse. Trata-se justamente da pulsão dessubjetivante, algo que acomete seu corpo sem que tenha notícia. Ela é serva da pulsão ${ }^{12}$, o efeito sujeito não se produz. Quando chega para atendimento, L.D. é quase monossilábica. A única frase que repete é em referência a ter vindo porque a médica disse que só ali teria a solução para a sua dor: "a doutora me mandou vir porque nenhum remédio funciona e ela disse que aqui a senhora vai resolver meu problema". Seu discurso empobrecido aponta para o empobrecimento de sua vida. "Tenho setenta anos", diz, referindo-se à vida de alguém trinta anos mais velha, que representa para ela a abdicação da sexualidade com todas as suas implicações. Ao mesmo tempo, L.D. demonstra certa negação dos limites com que se depara dado que está em tratamento oncológico. Por exemplo, ao falar de seu trabalho com desportistas afirma: "tenho que aparentar saúde". E completa: "levo uma vida normal. Sou uma pessoa saudável, por isso faço todas as coisas que todas as pessoas fazem". Com isso, força-se (ou força seu corpo) para além da recomendação médica, tomando para si afazeres domésticos pesados que poderiam ser de responsabilidade de outros na casa. Neste ponto, cabe questionar a repercussão que tem para a concepção de seu corpo o fato de ele ter sido modificado pelo câncer. E, mais ainda, nos perguntamos se podemos falar de um efeito sujeito nesse caso ou se estamos frente justamente a um apagamento subjetivo. L.D. é alguém que não quer saber, a ponto de não sentir dor, do eu corporal, do sujeito do desejo.
Durante o processo de atendimento com a psicóloga, L.D. começa aos poucos a falar, e ao dizer há um ligeiro deslocamento em sua posição subjetiva. A menção à dor agora passa a um plano secundário, às vezes até desaparece, dando lugar à elaboração de questões estruturais que remetem, por exemplo, à perda de sua mãe, com a mesma afecção. A dor, insuportável quando de sua chegada, logo em seguida considerada enigmática por sua ausência anterior, ganha outro estatuto ou chega a perder a importância que tinha. Ela passa a não ser mais insuportável, a médica consegue controlá-la e sua fala durante os atendimentos dá lugar a questões, às vezes muito duras, mas que paradoxalmente dão mais mobilidade à vida, causando uma pequena mudança no lugar em que se exerce como sujeito.

$\mathrm{Na}$ melhor das hipóteses, desvencilhado de um funcionamento pulsional acéfalo, o sujeito pode querer tratar essa pulsão de modo diverso, a partir de ter se submetido e tomado lugar aí, como efeito de ritmo pulsional, e vir a dar a isso, quem sabe, um outro destino ${ }^{12}$. Pode-se localizar aí o processo da pulsão subjetivante. Vale mais uma vez sustentar que, se a pulsão subjetivante tem como efeito um sujeito, é isso o que está em jogo quando se trata de "ritmar o tratamento"13, ou seja, que, se reconhecendo como efeito de ritmo pulsional, um sujeito desejante possa advir. O que implica sair da posição alienante, adormecido quanto a seu desejo, inteiramente sob o comando da pulsão acéfala. Então, se necessariamente intervenções radicais e invasivas no corpo afetam o funcionamento pulsional, essas são questões que se colocam sobre o ritmo e a pulsão nas intervenções no corpo, que têm efeito no eu corporal, ou seja, na subjetividade.

O que se coloca para o nosso estudo é o efeito que terá na posição subjetiva o encontro com algo que atinja radicalmente a anatomia. Se, para a constituição corporal, é necessária essa operação subjetiva, de que maneira um tumor que se instala no corpo afeta o psíquico no ser falante o que acontece a essa operação subjetiva pela ligação desse sujeito com um corpo que se apresenta enfermo?

"É um peso, tenho muitas dores nas costas", diz Z., paciente em cuidados paliativos - acompanhada pela equipe multiprofissional do Hospital do Câncer IV (Unidade de Cuidados Paliativos do INCA), em uma prática que, apenas por ser interdisciplinar, deu as condições para que o sofrimento da paciente pudesse ser enfrentado por ela própria e também pela equipe que a acolheu. "Mas o que mais me incomoda é o cheiro. Estou 
sentindo agora, mesmo com o curativo. Cheiro de água de salmoura, de carne podre: carniça”. Conta de um banho no chuveiro: "Eu olhava para trás, no chão, e via os pedaços de carne, assim, escorrendo..." E, depois acrescenta: "tem mulher que não deixa o marido ver. Eu não, fico à vontade em casa. Ele faz até o curativo. Não tem nada a ver não". "O meu marido fala para as pessoas: 'O meu casamento acabou'. Aí eu falo que não". Por outro lado, chama a atenção que ela diga: "às vezes, eu choro em casa, falo que tudo acabou. Aí meu marido diz que não, que não acabou".

Com a afirmação do marido, de que o casamento acabou, ela traz o estremecimento em sua posição de mulher. Ela diz ainda que: "o namoro acabou" (remetendo-se à relação sexual). Mas, como vimos, acredita também que "não tem nada a ver" - ou a velar. Essas são frases que indicam, no desvelamento explícito, o abalo no que é da ordem do sexual. Ao falar do casamento e do "namoro", traz questões, em processo de elaboração, sobre o seu lugar - ou sua perda de lugar.

Os pedaços de carne escorrendo no ralo estão na própria operação que terá feito dela, neste momento, sujeito. Dito de outro modo, é por isso aparecer em suas palavras que, por radical que seja, aí mesmo se constrói o lugar de um novo sujeito, com um corpo agora afetado pela doença. Trata-se disso, ou do pior. Pois, se não é recolhendo nesses pedaços de carne e nesse tateamento ("acabou", "não acabou", "não deixa ver", "não tem nada a ver") que ela se faz sujeito, ela não teria lugar, já que não há mais o lugar de antes, a que possa retornar.

Se para haver constituição corporal é preciso uma operação, então, algo que atinja radicalmente a anatomia (como um tumor), terá necessariamente efeitos na posição subjetiva do ser falante - sua relação com o Outro, suas modalidades discursivas, suas condutas sexuais e suas relações com os outros -, uma vez que isso atualiza a posição do sujeito frente à castração.

\section{A faca só lâmina daquele que escuta ou submeter-se a escutar na compaixão}

Encontramos na Clínica da Dor um lugar onde as questões do sofrimento psíquico podem se expressar de forma contundente, instando os profissionais a enfrentá-las. Todavia, nem sempre a dor aí implicada é facilmente reconhecida. Trata-se, para aquele que assiste o paciente, de reconhecer em sua fala o padecimento e muitas vezes a angústia que o acompanha. Faz-se necessária a escuta do sofrimento psíquico, pois é ela que em algum ponto possibilita sua elaboração, muitas vezes viabilizando no mesmo ato o tratamento oncológico ${ }^{25}$.

Logo, escutar é dar as condições para que no trabalho com esse outro, que é o paciente, a palavra seja dita. Oferecer-lhe a escuta e, em consequência, fazer valer sua palavra, constitui-se em um meio crucial de dar-lhe o lugar, em que, se ele se depara com a aridez do que enfrenta, virá a se responsabilizar por sua condição inexorável de sujeito ao corpo.

Ora, justamente aqui, se coloca a pungente pergunta: que implicações isto traz para aquele que ao dar lugar ao sujeito compartilha com ele a dureza que o travessa. Emprestar sua escuta coloca ao profissional uma exigência que certamente não será sem ônus para si próprio. Vimos como há um efeito de real no corpo, quando o sujeito é surpreendido pelo câncer. Esse real carrega a angústia de castração, a transitoriedade da vida, sua finitude e, paradoxalmente, o desejo. O desejo de um sujeito que é chamado a se posicionar frente a todas estas questões (acerca das quais, na maior parte das vezes, nada queremos saber). É isso que será escutado e levantará, para aquele que escuta, essas mesmas dificuldades, sem que muitas vezes se dê conta, já que, como observamos, o corpo e as questões que ele porta são deixados sob o recalque.

Nesse sentido, estão em jogo para nós profissionais duas posições: a primeira diz respeito ao sentimento de pena que se pode ter daquele que chega com seu padecimento, a segunda, se nos decidimos pela escuta do sofrimento de um outro, refere-se à compaixão com que o acolhemos. Enquanto a pena está referida ao ódio, intrínseco à dualidade - ou eu ou ele -, a compaixão diz respeito a uma posição terceira, para falar da qual usamos a imagem de uma faca só lâmina que corta dos dois lados. Esta é uma imagem forte que nos faz ver que se a castração (ou o que estamos reconhecendo como os limites presentes na vida de cada um) está colocada para o paciente, ela está também, e, talvez, antes de tudo, para aquele que escuta ${ }^{13}$. Isso não é escutado sem que haja repercussões em cada um que o faz. Trata-se, portanto, de uma reflexão imprescindível para o trabalho em instituição oncológi$\mathrm{ca}$, na medida em que somos atingidos por essa dimensão de "faca só lâmina"13.

Abordar um paciente, sem qualquer possibilidade curativa de uma doença que só faz avançar, abordá-lo para que possa "se adaptar à sua nova situação", valorizando o que "ainda pode fazer", é recebê-lo a partir de uma posição de 
pena. Pena é comiseração desdenhosa, marca principalmente desprezo e não compaixão. Nas palavras de Molière ${ }^{26}$ : "Considerar com desprezo misturado de vaga compaixão". E nas de Balzac' 26: "A pena mata, enfraquece ainda mais nossa fragilidade. É o mal tornado embustido, é o desprezo na ternura". Há na pena o desdém e o desprezo, daquele que, defendido, se crê inteiro frente ao outro mutilado (às vezes literalmente). Considerar a desolação que transpassa o paciente como digna de pena é uma tentativa de dissimular, para si próprio, o horror impactante e o impossível aí em jogo, isto é, o inexorável da morte. A pena sustenta um eu que se considera inteiro, aquele que procura sempre evitar as questões postas pela morte e pelo sexual.

Expressar pena cala o sujeito porque fecha qualquer espaço de construção de fala, que toque no real do que experimenta. Isso poupa, especialmente, o clínico, porque a fragilidade e a falta de qualquer garantia de se estar a salvo disso são compartilhadas por todos nós - é do que, como estamos repetidamente observando, nada se quer saber. Embora possa ser "confortável" para o profissional e para os que estão em volta, isso significa a morte do sujeito, que, emudecido, não encontra lugar de expressão, muitas vezes antecipando, subjetivamente, a morte concreta.

Já a compaixão implica sofrer juntamente, tomar parte no sofrimento do outro, do latim compatio, sofrimento comum ${ }^{27}$. Do mesmo modo, vem, do grego, simpatia [sym, juntamente, e páthos, paixão]. Páthos é o que se experiencia, tudo o que, bem e mal, afeta o corpo ou a alma e move o sujeito ${ }^{26}$. O cheiro da carniça é cortante no discurso da paciente. A direção do trabalho, com ela, consistiu em sustentar um lugar de palavra, o que permitiu o endereçamento e a produção mesma de sua fala. Não há cura, não há garantia, há fragilidade, desamparo e solidão. A aposta é a de que o sujeito possa sofrer isso não tão sozinho. Encontrar alguém a quem endereçar a sua palavra pode ter como efeito tomar o real (do câncer, do corpo, da morte) com os recursos dados pelo simbólico (da palavra, do significante, da construção da história do sujeito), o que o terá feito elaborar minimamente algo do horror que o atinge.

Z. tem um tumor de mama enorme, carniça entranhada em seus órgãos nobres, da qual não pode se livrar com vida. Ela nos diz que a carniça não é dela, não a é. Viabilizar um espaço para a escuta permitiu que ela pudesse falar da carniça, que não era dela, e da dor de carregá-la. Não há como livrá-la da carne apodrecida, nem no real do corpo nem no simbólico da palavra. Mas, em uma tessitura, fez-se possível tratar o real que afeta o corpo pelo simbólico, ao por em palavra e escrever sua história (que permanece e nos coloca a trabalhar, ao ser contada aqui). É isso, ou o pior: atravessá-lo sem companhia na surdez acachapante, que só pode impor o mutismo.

Ao contrário, faz-se muitas vezes um "contrato" de não perturbar os demais com o insuportável. Todos se comprometem em não abordá-lo, muitas vezes procurando uma compensação na valorização das capacidades que não foram perdidas, calando a dor e a possibilidade de sua elaboração pela via da palavra. Ou, ao invés disso, se trata de acompanhar Z. em seu desbravamento, sem saber de antemão os caminhos a serem trilhados e se responsabilizar por isso, dando suporte ao que daí advier. Não há solução, mas fragmento, pedaço de um percurso, na construção de uma história, na escrita do sujeito. Aí estão os limites e possibilidades do trabalho: não há o que se dê à paciente, de conforto, de paliação, como encobrimento disso que é. Resta acompanhá-la na travessia, tomar parte no que a afeta como testemunha.

Lispector ${ }^{28}$ escreve: "E conformar-se sem se resignar. (...) E então vem o desamparo de se estar vivo. Estou falando da angústia mesmo, do mal. Porque alguma angústia faz parte: o que é vivo, por ser vivo, se contrai". Trata-se de se conformar (do latim conformare, submeter-se) com aquilo que é - o inexorável -, e, justamente nisso, está a liberdade do sujeito, se assim se decidir, de se responsabilizar pelo que lhe acontece, portanto, sem resignação (do latim resignare, demitir-se) ${ }^{26}$.

Podemos concluir com a formulação: o clínico, também dividido e sujeito ao desamparo de se estar vivo, submete-se ao inexorável, e, desse lugar, partilha do páthos. Dito de outro modo, pode-se escolher submeter-se e escutar na compaixão ou demitir-se na pena e fazer calar. É na penúria daquele que escuta que opera o fio cortante da faca só lâmina.

\section{Colaboradores}

JM Castro-Arantes e AC LoBianco trabalharam na concepção teórica, na elaboração teórica e na redação final do artigo. 


\section{Referências}

1. Nasio JD. A dor física. Rio de Janeiro: JZE; 2008.

2. Thibierge S. Le nom, l'image, l'objet. Paris: PUF; 2011.

3. Topkanou I. Au-delà des apparences, y a-t-il une vérité don't le corps serait le lieu? Journal Français de Psychiatrie 2011; 35:19-23.

4. IASP-International Association for the Study of Pain [Internet]. Washington: Pain definitions. [updated 2012 May 22,] [cited 2013 February 16]. Available from: www.iasp-pain.org/AM/Template.cfm?Section $=$ Pain_Definitions

5. McCaffery M, Beebe A. Pain: Clinical Manual for Nursing Practice. St. Louis, MO: C. V. Mosby; 1989.

6. Freud S. Tres ensayos de teoría sexual (1905). In: Freud S. Sigmund Freud Obras completas, V.7. Buenos Aires: Amorrortu editores; 1996. p.117-210.

7. Freud S. Pulsiones y destinos de pulsiones (1915). In: Freud S. Sigmund Freud Obras completas, V.15. Buenos Aires: Amorrortu editores; 1996. p.113-134.

8. Freud S. El yo y el ello (1923). In: Sigmund Freud Obras completas (vol. 19). Buenos Aires: Amorrortu editores; 1996. p. 1-66.

9. Lacan J. L'instance de la lettre dans l'inconscient ou la raison depuis Freud. In: Lacan J. Écrits. Paris: Seuil; 1966. p. 493-530.

10. Lacan J. Fonction et champ de la parole et du langage em psychanalyse. In: Lacan J. Écrits. Paris: Seuil; 1966. p. 237-322

11. Lacan J. Le séminaire livre 7, L'éthique de la psychanalyse (1959-1960). Paris: Seuil; 1986.

12. Melman Ch. La question du corps en psychanalyse. Bulletin de l'Association freudienne internacionale 2001; 94:7-15.

13. Czermak M. Patronimias. Rio de Janeiro: Editora Tempo Freudiano; 2012.

14. Lacan J. O seminário livro 23, O sinthoma (19751976). Rio de Janeiro: JZE;2007.

15. Jean T. Pulsão, gozo, representação e anorexia. In: Czermak M, Tysler JJ, organizadores. A pulsão na psicose: oralidade, mania e melancolia. Rio de Janeiro: Editora Tempo Freudiano; 2009. p. 95-100.

16. Freud S. Introducción del narcisismo (1914). In: Freud S. Sigmund Freud Obras completas (vol.14). Buenos Aires: Amorrortu editores; 1996. p. 71-98.
17. Canguilhem G. O normal e o patológico. Rio de Janeiro: Forense Universitária, 2002.

18. Lacan J. Le séminaire livre 11, Les quatre concepts fondamentaux de la psychanalyse (1964-1965). Paris: Seuil; 1973.

19. Freud S. La transitoriedad (1916). In: Freud S. Sigmund Freud Obras completas, V.14. Buenos Aires: Amorrortu editores; 1996. p. 309-312.

20. Freud S. Nuestra actitud hacia la muerte (1915). In: Freud S. Sigmund Freud Obras completa, V.14. Buenos Aires: Amorrortu editores; 1996. p.290-301.

21. Lacan J. Le séminaire livre 5, Les formations de l'inconscient (1957-1958). Paris: Seuil,1998

22. Siqueira-Batista R, Schramm FR. A eutanásia e os paradoxos da autonomia. Cien Saude Colet 2008; 13(1):207-221.

23. Tyszler JJ, organizador. A pulsão na psicose: oralidade, mania e melancolia. Rio de Janeiro: Editora Tempo Freudiano; 2009.

24. Vandermersch B. Pulsão e gozo. In: Czermak M, Tysler JJ, organizadores. A pulsão na psicose: oralidade, mania e melancolia. Rio de Janeiro: Editora Tempo Freudiano; 2009. p. 83-94.

25. Garcia APRF, Nosawa MR, Marques D. As práticas de saúde de família discutidas na perspectiva da psicanálise: uma proposta de cuidado. Cien Saude Colet 2010; 15(Supl. 1):1481-1486.

26. Rey A. Dictionnaire historique de la langue française. Paris: Le Robert; 2004.

27. Siqueira-Batista R, Schramm FR. A bioética da proteção e a compaixão laica: o debate moral sobre a eutanásia. Cien Saude Colet 2009; 14(4):1241-1250.

28. Lispector C. Outros escritos. Rio de Janeiro: Rocco; 2005.

Artigo apresentado em 28/04/2013

Aprovado em 22/05/2013

Versão final apresentada em 22/05/2013 